\title{
Sensitization to the Lysosomal Cell Death Pathway upon Immortalization and Transformation
}

\author{
Nicole Fehrenbacher, ${ }^{1}$ Mads Gyrd-Hansen, ${ }^{1}$ Birgit Poulsen, ${ }^{1}$ Ute Felbor, ${ }^{2}$ Tuula Kallunki, ${ }^{1}$ Marianne Boes, ${ }^{3}$ \\ Ekkehard Weber, ${ }^{4}$ Marcel Leist, ${ }^{5}$ and Marja Jäättelä ${ }^{1}$
}

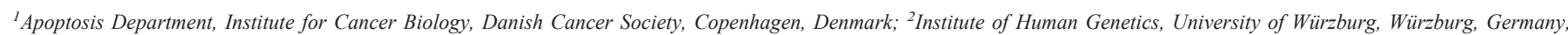

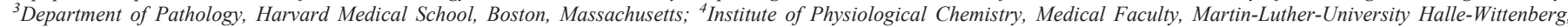
Halle, Germany; and ${ }^{5}$ Disease Biology, H. Lundbeck A/S, Valby, Denmark

\begin{abstract}
Tumorigenesis is associated with several changes that alter the cellular susceptibility to programmed cell death. Here, we show that immortalization and transformation sensitize cells in particular to the cysteine cathepsin-mediated lysosomal death pathway. Spontaneous immortalization increased the susceptibility of wild-type murine embryonic fibroblasts (MEFs) to tumor necrosis factor (TNF)-mediated cytotoxicity $>1000$-fold, whereas immortalized MEFs deficient for lysosomal cysteine protease cathepsin $B$ (CathB) retained the resistant phenotype of primary cells. This effect was specific for cysteine cathepsins, because also lack of cathepsin L (a lysosomal cysteine protease), but not that of cathepsin D (a lysosomal aspartyl protease) or caspase-3 (the major executioner protease in classic apoptosis) inhibited the immortalization-associated sensitization of MEFs to TNF. Oncogene-driven transformation of immortalized MEFs was associated with a dramatic increase in cathepsin expression and additional sensitization to the cysteine cathepsin-mediated death pathway. Importantly, exogenous expression of CathB partially reversed the resistant phenotype of immortalized CathB-deficient MEFs, and the inhibition of CathB activity by pharmacological inhibitors or RNA interference attenuated TNF-induced cytotoxicity in immortalized and transformed wild-type cells. Thus, tumorigenesis-associated changes in lysosomes may counteract cancer progression and enhance therapeutic responses by sensitizing cells to programmed cell death.
\end{abstract}

\section{INTRODUCTION}

Until recently, caspase activation has been considered as an indispensable hallmark of programmed cell death (PCD; Ref. 1). Accumulating data suggest, however, that caspase-dependent apoptosis is only one of many ways a cell can commit suicide (reviewed in Refs. 2, 3). Alternative caspase-independent cell death pathways have been especially well documented in response to the activation of death receptors of the tumor necrosis factor receptor (TNF-R) family (reviewed in Refs. 4, 5). The inhibition of caspase activation by the following means fails to rescue the cells from death receptor-induced PCD: (a) pharmacological caspase inhibitors in immortalized and transformed fibroblasts and several tumor cell lines $(6,7) ;(b)$ genetic depletion of caspase-8 in leukemic Jurkat T cells (8); (c) expression of a dominant-negative mutant of Fas-associated death domain protein in immortalized fibroblasts and tumor cells (9); and $(d)$ inhibition of apoptosome formation by ATP depletion in Jurkat cells (10). Instead, the interference with the caspase-mediated apoptosis pathway either enhances the apoptosis-like death or changes the morphology of the dying cells from apoptotic to necrotic in these model systems. The

Received 4/22/04; accepted 5/28/04.

Grant support: The Danish Cancer Society (N. Fehrenbacher, M. Jäättelä and T. Kallunki), the Danish Medical Research Council (M. Jäättelä), the Association for International Cancer Research (M. Jäättelä), the Nordic Academy for Advanced Study (M. Jäättelä), the Novo Foundation (M. Jäättelä), and an Emmy Noether grant from the German Research Foundation (U. Felbor).

The costs of publication of this article were defrayed in part by the payment of page charges. This article must therefore be hereby marked advertisement in accordance with 18 U.S.C. Section 1734 solely to indicate this fact.

Requests for reprints: Marja Jäättelä, Apoptosis Department, Institute for Cancer Biology, Danish Cancer Society, Strandboulevarden 49, DK-2100 Copenhagen, Denmark. Phone: 45-35257318; Fax: 45-35257721; E-mail: mj@cancer.dk. signaling pathways involved in the death receptor-induced caspaseindependent PCD are, as yet, poorly elucidated, but accumulating data point to the lysosomal proteases, cathepsins, as major executioners especially in tumor cells $(7,11,12)$.

In addition to their role in general protein turn-over and tumor cell invasion, lysosomes function as death signal integrators in various forms of PCD (reviewed in Refs. 5, 13, 14). Lysosomal proteases, cathepsins, translocate from the lysosomal lumen to the cytosol in response to a wide variety of death stimuli such as death receptor activation ( $7,15,16)$, p53 activation (17), microtubule-stabilizing agents (18), oxidative stress and growth factor deprivation (19), staurosporine (20), and so forth. Once released to the cytosol, cathepsins, especially cysteine cathepsins B and L and aspartyl cathepsin $\mathrm{D}$, can trigger the whole spectrum of death morphologies from necrosis to classic apoptosis. The outcome depends on the extent of the lysosomal membrane permeabilization and the amount of cathepsins released to the cytosol. In addition to the completely caspase-independent death pathways $(7,20,21)$, cathepsins can also participate in apoptosis-like PCD either upstream $(15,16,22)$ or downstream $(7)$ of mitochondrial alterations and effector caspase activation. Furthermore, cathepsin B (CathB) can directly activate the inflammatory caspases, caspase-1, and caspase-11, whereas the proapoptotic caspases appear as poor substrates for most cysteine cathepsins (21). A more likely link between cathepsins and the activation of proapoptotic caspases is the activating cleavage of Bid, a BH3-only member of the Bcl-2-family, by cysteine cathepsins and the following permeabilization of the mitochondrial outer membrane that allows the release of cytochrome $c$ and caspase activation (23).

The activation of most transforming oncogenes as well as the loss of function of several tumor suppressor genes results initially in increased sensitivity to classic caspase-dependent apoptosis (24). The aim of this study was to investigate whether tumorigenesis-associated changes also sensitize cells to the lysosomal death pathway. For this purpose, we established several murine embryonic fibroblast lines from wild-type (WT) mice and mice deficient for various cathepsins and caspases. All of the cell lines were allowed to spontaneously immortalize, and they were tested for the sensitivity to TNF-induced PCD before and after the immortalization. Prompted by the striking results showing that $\mathrm{CathB}$ played a major role in the immortalizationassociated sensitization to TNF-induced death, we analyzed the ability of individual immortalizing and/or transforming oncogenes to do the same. The results obtained provide strong evidence supporting the hypothesis that immortalization and transformation sensitize cells to the CathB-dependent lysosomal death pathway.

\section{MATERIALS AND METHODS}

Cell Culture and Treatments. Primary murine embryonic fibroblasts (MEFs) explanted from day 14 to day 16, CathB-, D- (kindly provided by Dr. Peter Saftig, Christian-Albrechts-University, Kiel, Germany and Dr. Christoph Peters, Albert-Ludwigs-University, Freiburg, Germany; Ref. 25), L- (Astra Zeneca, Cheshire, United Kingdom), and caspase-3-deficient (kindly provided Drs. Stephane Hunot and Richard Flavell, Yale University, New Haven, CT; 
Ref. 26), and corresponding WT embryos of C57BL/6 $\times 129$ mixed background (Table 1) were split once a week $\left(6-8000\right.$ cells $\left./ \mathrm{cm}^{2}\right)$ with a change of medium on day 3 until they reached senescence. Senescent cells were maintained by medium change twice a week, and appropriate splitting was restarted on reappearance of growth. The immortalized murine embryonic fibroblasts (iMEFs) were used at passages 16-28. The appropriate phenotypes of iMEFs were confirmed by immunoblotting and/or reverse transcription-PCR. Spontaneously immortalized MEFs (passage 16) were not able to form tumors in nude mice after s.c. injection. All of the animal work was carried out in accordance with the NIH guidelines. NIH3T3 fibroblasts were kindly provided by Christian Holmberg (University of Copenhagen, Copenhagen, Denmark). DMEM with Glutamax (Life Technologies, Inc.) supplemented with 10\% heat-inactivated FCS, $0.1 \mathrm{~mm}$ nonessential amino-acids (Life Technologies, Inc.), and antibiotics were used as growth medium for MEFs and is referred to as complete medium. Cells were cultured at $37^{\circ} \mathrm{C}$ in a humidified air atmosphere with $5 \% \mathrm{CO}_{2}$.

Recombinant human TNF (hTNF) was kindly provided by Anthony Cerami (Kenneth Warren Laboratories, Tarrytown, NY), recombinant murine tumor necrosis factor was from R\&D Systems (United Kingdom), and staurosporine and cycloheximide (CHX) from Sigma-Aldrich (St. Louis, MO). The z-Phe-Ala-fluoromethylketone (zFA-fmk; Enzyme Systems, Livermore, CA), z-Val-Ala-DL-Asp-fmk (zVAD-fmk), and $N$-acetyl-Asp-Glu-Val-Aspchlorometylketone (DEVD-cmk; Bachem, Switzerland), PD 150606 (Calbiochem-Novabiochem Co., La Jolla, CA), CA-074-Me (Peptides International, Louisville, KY), $N$-acetyl-Leu-Leu-Nle-aldehyde (ALLN; Calbiochem, San Diego, CA), $N$-acetyl-Asp-Glu-Val-Asp-aldehyde (DEVD-CHO; Neosystems, Strasbourg, France), $N$-acetyl-Ile-Glu-Thr-Asp-aldehyde [IETD-CHO; Sigma (A-1216)], pepstatin A, $N$-a-tosyl-L-Lys-chloromethylketone, and $N$-tosyl-LPhe-chloromethylketone (TLCK and TPCK, Boehringer Mannheim, Germany) were dissolved in DMSO and added $1.5 \mathrm{~h}$ or $24 \mathrm{~h}$ (pepstatin A) before the experiment. The final DMSO-concentration was $0.2-0.5 \%$, and all of the samples were adjusted accordingly.

Viability Assays. The viability and death of subconfluent cells were analyzed by the 3-(4,5-dimethylthiazole-2-yl)-2,5-diphenyltetrazolium bromide

Table 1 Characterization of IMEFs $^{a}$ (passages 18-26) used in this study Averages \pm SD from 5 (WT, CathB ${ }^{-1-}$, and CathL ${ }^{-1-}$ ), 3 (CathD $^{-1-}$, Casp-3), or 2 (NIH3T3) independent triplicate experiments are shown.

\begin{tabular}{|c|c|c|c|c|c|}
\hline Genotype & $\mathrm{p} 53^{b}$ & $\mathrm{p} 19^{c}$ & Ploidy $^{d}$ & $\begin{array}{l}\text { Viability }{ }^{e} \text { after } \\
\text { TNF }+ \text { CHX }\end{array}$ & $\begin{array}{c}\text { Cytotoxicity }^{f} \text { after } \\
\text { TNF + CHX }\end{array}$ \\
\hline WT-1 & low & - & Diploid & $8.1 \pm 4.3$ & $52.2 \pm 9.1$ \\
\hline WT-2 & low & - & Diploid & $27.3 \pm 17.8$ & n.d. \\
\hline WT-3 & high & + & Aneuploid & $20.9 \pm 13.8$ & $67.6 \pm 9.2$ \\
\hline WT-4 & high & + & Aneuploid & $48.0 \pm 12.3$ & $32.8 \pm 9.1$ \\
\hline WT-6 & high & + & Aneuploid & $11.0 \pm 11.0$ & $42.0 \pm 12.7$ \\
\hline WT combined & & & & $22.1 \pm 18.2$ & $48.7 \pm 14.9$ \\
\hline $\mathrm{CathB}^{-1-}-1$ & low & - & Diploid & $81.7 \pm 10.2$ & $9.1 \pm 10.2$ \\
\hline CathB $^{-1-}-2$ & low & - & Diploid & $73.5 \pm 2.3$ & $13.3 \pm 3.9$ \\
\hline $\mathrm{CathB}^{-1-}-3$ & low & - & Diploid & $49.5 \pm 11.0$ & $18.7 \pm 3.8$ \\
\hline $\mathrm{CathB}^{-1-}-4$ & low & - & Diploid & $94.5 \pm 10.3$ & $15.9 \pm 9.7$ \\
\hline CathB $^{-1-}$ combined & & & & $82.3 \pm 8.8^{g, h}$ & $14.2 \pm 4.1^{g}$ \\
\hline CathL $^{-1-}-1$ & high & + & Aneuploid & $76.2 \pm 5.8$ & $12.03 \pm 6.0$ \\
\hline $\mathrm{CathL}^{-1-}-2$ & low & - & Diploid & $45.4 \pm 6.6$ & $20.32 \pm 16.6$ \\
\hline CathL $^{-1-}$ combined & & & & $60.8 \pm 21.8^{g}$ & $16.2 \pm 5.9^{g}$ \\
\hline CathD $^{-1-}$ & n.d. & n.d. & n.d. & $41.0 \pm 15.7$ & n.d. \\
\hline Casp3 ${ }^{-1-}$ & high & + & Aneuploid & $14.5 \pm 6.4$ & $52.5 \pm 10.3$ \\
\hline NIH3T3 & low & - & Diploid & $39.1 \pm 4.7$ & n.d. \\
\hline
\end{tabular}

${ }^{a}$ iMEFs, immortalized murine embryonic fibroblasts; TNF, tumor necrosis factor; CHX, cycloheximide; WT, wild-type low expression; n.d., not detected; mut, mutated high expression; Cath, cathepsin; Casp, caspase; +, detectable; -, undetectable; MTT, 3-(4,5-dimethylthiazole-2-yl)2,5-diphenyltetrazolium bromide; MTNF, murine tumor necrosis factor.

${ }^{b}$ The expression levels of p53 were detected by immunoblot analysis.

${ }^{c} \mathrm{p} 19^{\mathrm{ARF}}$ were detected by immunoblot analysis.

${ }^{d}$ The ploidy of iMEFs was analyzed by flow cytometry analysis of the cellular DNA content.

${ }^{e}$ The viability (MTT reduction assay) of cells were analyzed $17 \mathrm{~h}$ after treatment with $1 \mathrm{ng} / \mathrm{ml} \mathrm{mTNF}$ plus $5 \mu \mathrm{M}$ CHX.

${ }^{f}$ The cytotoxicity (lactate dehydrogenase release assay) of the cells were analyzed $17 \mathrm{~h}$ after treatment with $1 \mathrm{ng} / \mathrm{ml} \mathrm{mTNF}$ plus $5 \mu \mathrm{M}$ CHX.

${ }^{g} p$-value $<0.01$

${ }^{h}$ Averages of the viability and cytotoxicity after TNF plus CHX treatment of $5 \mathrm{WT}$, four CathB $-/-$ and 2 CathL- - - iMEF lines were statistically analyzed by the one-way ANOVA with WT cells as reference group.
(MTT) reduction and lactate dehydrogenase (LDH; cytotoxicity detection kit from Roche) assays essentially, as described previously (7). The viability is displayed as a percentage of $\mathrm{CHX}$-treated cells and the cytotoxicity as a percentage of LDH released to the supernatant of the total LDH (LDH in the supernatant $+\mathrm{LDH}$ in the lysate). The assays were performed in complete medium (RPMI 1640 instead of DMEM), and optical density changes were measured with a Versamax microplate reader (Molecular Devices Ltd., Wokingham, United Kingdom). Apoptotic cells (condensed chromatin and intact plasma membrane) were identified using an inverted Olympus IX70 fluorescent microscope (filter U-MWU, 330-385 nm) after staining the cells with a mixture of $2.5 \mu \mathrm{g} / \mathrm{ml}$ Hoechst 33342 and $2.5 \mu \mathrm{M}$ SYTOX (Molecular Probes) as described previously (10).

TNF Binding, Degradation, and Signaling. For the analysis of TNF receptor binding and degradation subconfluent cells were trypsinized, washed and incubated at a density of $1 \times 10^{6}$ cells/ml DMEM plus $3 \%$ FCS containing $2 \mathrm{~nm}\left[{ }^{125} \mathrm{I}\right]$-hTNF $(188.8 \mu \mathrm{Ci} / \mu \mathrm{g}$; ICN Biomedicals, Costa Mesa, CA). After careful washing, cells were transferred to $37^{\circ} \mathrm{C}$, and the receptor-bound and degraded TNF were determined as described previously (27). For nuclear factor $\kappa \mathrm{B}(\mathrm{NF}-\kappa \mathrm{B})$ reporter assays, 30,000 cells were plated/24-well $20 \mathrm{~h}$ before the cotransfection with pRL-null (Promega) renilla luciferase internal standard plasmid and NF- $\kappa \mathrm{B}$-responsive pBIIX-Luc firefly luciferase reporter plasmid (28) and green fluorescent protein plasmid (pEGFP-C3; Clonetech) with LipofectAMINE Plus reagent (Life Technologies, Inc.). Cells were treated as indicated, and the cell lysates were prepared and luciferase activities measured with a luminometer (Lumat LB 9501; Berthold, Wildbad, Germany) according to the protocol from Promega.

For the c-Jun $\mathrm{NH}_{2}$-terminal kinase $(\mathrm{JNK})$ assay, cells were plated at the density of 35,000 cells $/ \mathrm{cm}^{2} 24 \mathrm{~h}$ before the indicated treatments, and the in-gel-kinase assay was performed essentially as described previously (29). Comparable JNK-expression levels were verified in WT and CathB-/iMEFs by immunoblotting (data not shown).

Protease Activity Measurements. NIH3T3 cells (40,000 cells/well in 24-well plates) and iMEFs (75,000 cells/well in 12-well plates) were plated $18 \mathrm{~h}$ before indicated treatments. After removing the medium, $300 \mu \mathrm{l}$ extraction buffer [250 mM sucrose, $20 \mathrm{~mm}$ HEPES, $10 \mathrm{~mm} \mathrm{KCl,} 1.5 \mathrm{~mm} \mathrm{MgCl}_{2}, 1$ mM EDTA, 1 mm EGTA, and $1 \mathrm{~mm}$ Pefabloc SC (pH 7.5)] containing 10-15 $\mu \mathrm{g} / \mathrm{ml}$ (cytoplasmic fraction; the digitonin concentration optimized to result in the total release of cytosolic proteins without disruption of lysosomes) or 200 $\mu \mathrm{g} / \mathrm{ml}$ (total cellular fraction) digitonin was added, and plates were kept on ice with gentle shaking for $10 \mathrm{~min}$. The enzyme activities of the samples were determined as described previously using z-Phe-Arg- and DEVD-7-aminotrifluoromethylcoumarin (zFR-afc and DEVD-afc; Enzyme System Products) as substrates for cysteine cathepsins and caspase-3-like caspases, respectively, and Spectramax Gemini fluorometer (Molecular Devices, Sunnyvale, CA) for the measurement of the $V_{\max }$ of the liberation of the fluorochrome (16). All of the protease activities were normalized to the LDH activity of the same sample.

Infections and Transfections. Retroviral vectors used included an empty pBabe-puro vector (a gift from Christian Holmberg), pBabe-puro-v-Ha-ras (a gift from Nikolaj Dietrich, University of Copenhagen, Copenhagen, Denmark), pBabe-puro-SV40-LT (a gift from Jennifer Rohn, LEADD, Leiden, The Netherlands), pBabe-puro-c-srcY527F constructed by subcloning the Src coding sequence from pSGT-c-srcY527F (a gift from Sarah Courtneidge, Van Andel Research Institute, Grand Rapids, MI; Ref. 30) into the EcoRI site in the pBabe-puro, and pBabe-puro-murine CathB (mCathB) constructed by a similar subcloning of the PCR-amplified CathB (NM 007798) from murine WEHI-S fibrosarcoma cells. Retrovira were produced in Phoenix helper-free ecotropic retrovirus-producing $293 \mathrm{~T}$ cells (a gift from Christian Holmberg) using a standard calcium phosphate transfection protocol, and viral infections were performed essentially as described previously (31). Experiments were performed after a 7-day selection with $2.5 \mu \mathrm{g} / \mathrm{ml}$ puromycine or when the transformed morphology was visible (Ras- and Src-transduced cells). Transient transfections were performed with oligofectamine (Invitrogen) according to the manufacturer's instructions. A small interfering RNA oligo-targeting mCathB (5'GACCUGCUUACUUGCUGUG-3') and a control oligo (5'CUUCUGGACAAGAAAAGGC-3') were synthesized at Dharmacon Research (Lafayette, CO). A plasmid encoding for a fusion protein consisting of histone 2B and enhanced green fluorescence protein (H2B-eGFP-N1; a gift from Christian Holmberg) was transfected with pBabe-puro or pBabe-puro-mCathB 
(1:8) to visualize the transfected cells and allow the counting of the condensed nuclei at an inverted fluorescence microscope (Olympus, IX-70).

Immunoblot Analysis and Immunocytochemistry. Immunodetection of proteins separated by SDS-PAGE and transferred to nitrocellulose was performed with enhanced chemiluminescence Western blotting reagents (Amersham International). The primary antibodies used included antirat CathB (32), anti-CathL (S-20; Santa Cruz Biotechnology Inc., Santa Cruz, CA), antiglyceraldehyde-3-phosphate dehydrogenase (Biogenesis, Poole, United Kingdom), anti-p53 (Ab-7; Oncogene Research Products, La Jolla, CA), anti-p19 Arf (ab80; Novus Biologicals, Littleton, CO), and anti-Hsp70 (2H9; a gift from Boris Margulis, Russia). Peroxidase-conjugated secondary antibodies were from Dako A/S

For immunocytochemistry, cells plated on glass cover slips were washed and fixed in ice-cold acetone-methanol $(1: 1)$ for $10 \mathrm{~min}$ at $25^{\circ} \mathrm{C}$ or in $4 \%$ formaldehyde in PBS for $20 \mathrm{~min}$ at $25^{\circ} \mathrm{C}$ followed by $10 \mathrm{~min}$ in $0.2 \%$ Triton X-100 in PBS (cytochrome $c$ staining). Samples were blocked with $10 \%$ FCS in PBS for $30 \mathrm{~min}$. Antibodies used included mouse anticytochrome $c$ (6H3.B4) and rat antimouse lysosome-associated membrane protein-1 (1D4B) from PharMingen, goat antirat CathB (32), and the appropriate Alexa-488- and Alexa-594-coupled secondary antibodies (Molecular Probes). Glass cover slips were mounted with antifade kit (Molecular Probes), and fluorescence images were taken with Zeiss 510 laser-scanning microscope with Axiovert 100M. Cells stained for cytochrome $c$ were additionally treated with RNase and stained with etidium bromide as described previously (16).

Analysis of Ploidy of iMEFs. Subconfluent cells were trypsinized, washed, resuspended in $300 \mu \mathrm{l}$ PBS plus 3\% FCS and fixed by adding $800 \mu \mathrm{l}$ ice-cold methanol. After $30 \mathrm{~min}$ at $4^{\circ} \mathrm{C}$, cells were washed in PBS plus $3 \%$ FCS, suspended in $200 \mu \mathrm{l}$ staining solution ( $50 \mu \mathrm{g} / \mathrm{ml}$ propidium iodide, $5 \mathrm{~mm}$ $\mathrm{MgCl} 2$, and $10 \mu \mathrm{g} / \mathrm{ml}$ DNase-free RNase), incubated for $30 \mathrm{~min}$ at $37^{\circ} \mathrm{C}$, and analyzed by flow cytometry (FACSCalibur; Becton Dickinson).

\section{RESULTS}

Immortalization Sensitizes MEFs to TNF-Induced CathBDependent and Caspase-3-Independent Cell Death. Contrary to some primary cells, TNF-induced death of several human and murine tumor cells depends on lysosomal proteases, cathepsins $(7,11,12)$. To study whether this difference could be because of cellular changes associated with immortalization, an essential part of the tumorigenesis process, primary cultures of WT MEFs as well as corresponding MEFs deficient for various cathepsins (CathB, CathL, and CathD) and caspase- 3 were established and run through a spontaneous immortalization protocol. The sensitivity of the cells to TNF plus CHX before and after the premature senescence crisis that occurred between passages 7 and 12 was measured by the MTT-viability assay. At passages before the crisis, MEFs deficient for CathB, CathL, CathD, and caspase-3 displayed a relatively TNF-resistant phenotype indistinguishable from that of WT MEFs (Figs. 1A; data not shown). The phenotype of the WT MEFs changed dramatically on immortalization from relatively TNF resistant to highly TNF sensitive (Figs. 1B). Contrary to WT MEFs, CathB ${ }^{-1-}$ MEFs retained their TNF-resistant phenotype on immortalization (Fig. $1 B$ ). The striking difference in the sensitivity of WT and $\mathrm{CathB}^{-1-}$ iMEF lines presented in the Fig. $1 B$ was observed in independent $\mathrm{iMEF}$ lines originating from five WT and four $\mathrm{CathB}^{-1-}$ embryos (Table 1). The TNF-resistant phenotype of $\mathrm{CathB}^{-1-}$ iMEFs observed in the MTT viability assay was additionally confirmed by the counting of apoptotic cells displaying condensed and fragmented chromatin (Fig. 1C) and by determining the
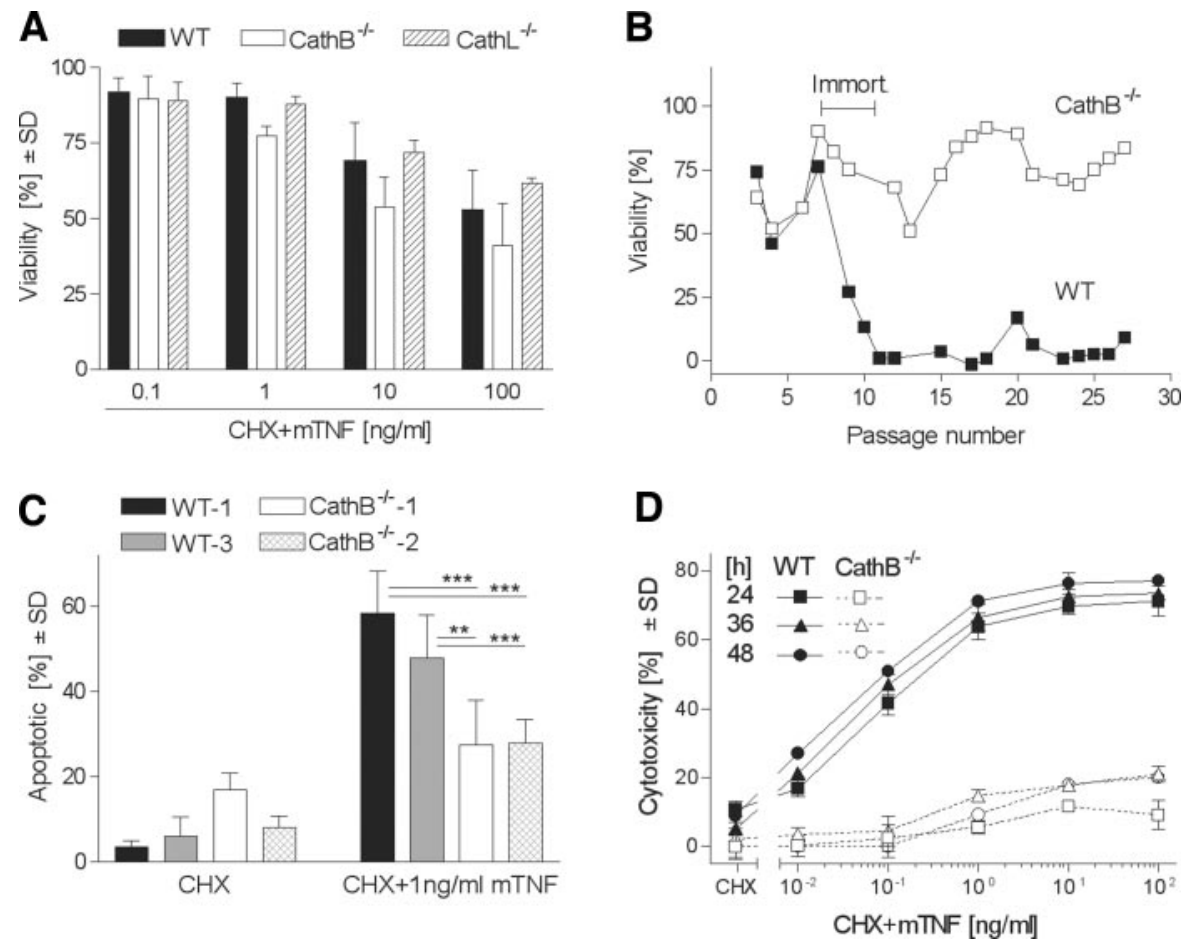

Fig. 1. Immortalization sensitizes murine embryonic fibroblasts (MEFs) to tumor necrosis factor-induced cathepsin B (CathB)-dependent cell death. $A$, primary MEFs (p2-5)

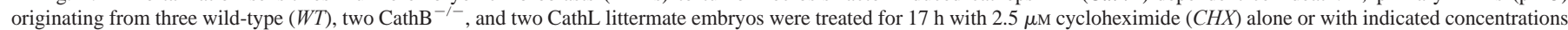

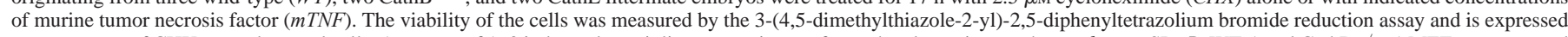

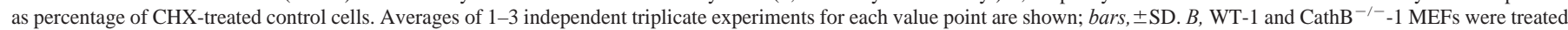

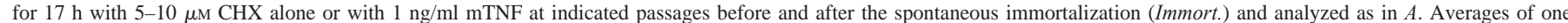

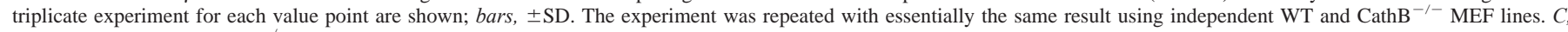

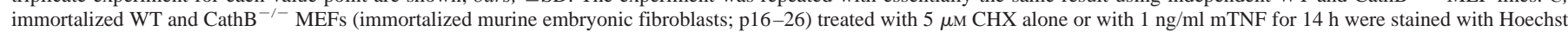

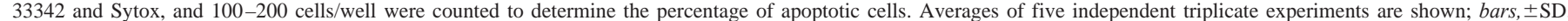

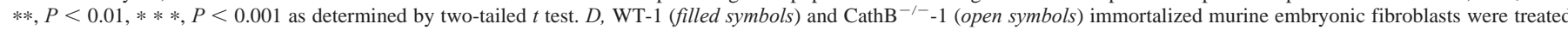

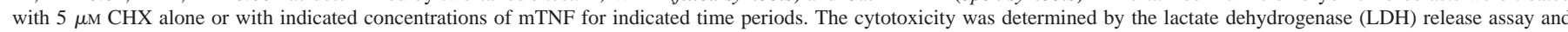

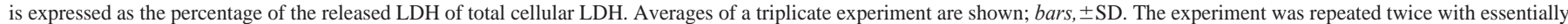
similar results. 
extent of the plasma membrane integrity by analyzing the LDH release from the cells (Fig. 1D; Table 1). Because of the growth inhibiting effects of $\mathrm{CHX}$, we were not able to test the clonogenic survival of TNF plus CHX-treated $\mathrm{CathB}^{-1-}$ iMEFs. The highly protected phenotype of $\mathrm{CathB}^{-/-}$iMEFs treated with TNF concentrations up to $100 \mathrm{ng} / \mathrm{ml}$ remained, however, for $48 \mathrm{~h}$ (the maximal time we could extend the assay to without unspecific toxicity induced by CHX), whereas the WT cells had died after $24 \mathrm{~h}$ (Fig. 1D). Also, iMEFs from CathL-deficient mice showed significantly increased resistance to TNF plus $\mathrm{CHX}$, whereas MEFs deficient for CathD and caspase-3 became sensitized to TNF plus CHX on immortalization in a manner indistinguishable from that seen in WT cells (Table 1).

The TNF-Sensitive Phenotype of iMEFs Depends on CathB. Next, we investigated whether the failure of TNF to kill iMEFs deficient for cysteine cathepsins was a direct consequence of cysteine cathepsin deficiency or an indirect effect of this genotype on the immortalization of MEFs. Genotype had no significant effect on the growth rate or morphology of the iMEFs (data not shown). The spontaneous immortalization of MEFs requires the inactivation of the p53signaling pathway (33). This can be achieved either directly by a mutation in the p53 gene or indirectly by the loss of the Ink4a-Arf gene locus that encodes two tumor suppressor proteins, $\mathrm{p} 16^{\text {Ink4a }}$ and p $19^{\text {Arf }}$ that are positive regulators of the retinoblastoma and p53 tumor suppressor gene products, respectively. Thus, we compared the changes in p53 and p19 Arf expression in iMEFs used in this study (Table 1). Immunoblot analysis revealed that three of five WT iMEF lines had mutated p53 and two had lost p19 Arf. All of the CathB ${ }^{-/-}$ iMEF lines had WT p53, but no detectable p19 ${ }^{\text {Arf }}$, and one CathL ${ }^{-1-}$ line had mutated p53 and the other had lost p19 ${ }^{\text {Arf }}$. On the basis of flow cytometry analysis of propidium iodide-labeled cells, all of the iMEFs with mutated p53 had aneuploid, whereas those lacking p19 ${ }^{\text {Arf }}$ had diploid chromosomes (Table 1). The differences in the immortalization process could not explain the differences in the TNF sensitivity between WT iMEFs and iMEFs deficient for CathB or CathL, because the TNF sensitivity of WT iMEF lines with loss of p19 Arf was similar to that of iMEF lines with mutated p53 (Table 1).

If the TNF-resistant phenotype of $\mathrm{CathB}^{-1-} \mathrm{iMEFs}$ was a direct effect of CathB deficiency, the ectopic expression of CathB should sensitize the cells to TNF. To test whether this was the case, we transduced $\mathrm{CathB}^{-1-}$ iMEFs with a retroviral vector containing mCathB cDNA under the long terminal repeat-promoter or an empty vector. After a 7-day selection with puromycin, the transduced cells were treated with $\mathrm{CHX}$ or TNF plus $\mathrm{CHX}$ for $17 \mathrm{~h}$, and their sensitivity to TNF was determined by MTT viability and LDH release assays. Immunocytochemistry of the transduced $\mathrm{CathB}^{-1-}$ iMEFs showed that over half of the cells expressed the ectopic CathB in the lysosomal compartment (colocalization with lysosome-associated membrane protein-1; Fig. 2A). Accordingly, a significant resensitization of $\mathrm{CathB}^{-1-}$ iMEFs to TNF was observed both in the LDH release assay and the MTT assay (Fig. 2, $B$ and $C$ ). For unknown reasons, the sensitization disappeared after two to three passages although CathB expression remained high. We speculated that the cells constitutively expressing high levels of ectopic CathB may be selected for resistance to CathB-dependent death pathway, and, therefore, we repeated the experiment using a transient expression system based on the coexpression of $\mathrm{CathB}$ and a fusion protein consisting of histone $2 \mathrm{~B}$ and enhanced green fluorescence protein (H2B-eGFP). This method allows the testing of the cells already 2-3 days after the
Fig. 2. Cathepsin B $(\text { CathB })^{-1-}$ immortalized murine embryonic fibroblasts (iMEFs) are resensitized to tumor necrosis factor by ectopic expression of CathB. $A-C$, CathB $^{-1-}-1$ iMEFs were transduced with a retroviral vector encoding for murine CathB $(m C a t h B ;$ black $)$ or an empty vector (white). Transduced cells selected with puromycin were analyzed for the expression and localization of mCathB by confocal microscopy with antiCathB (green) and antilysosome-associated membrane protein-1 (red; $A)$ and for the sensitivity to $5 \mu \mathrm{M}$ cycloheximide $(\mathrm{CHX})$ alone or with indicated concentrations of murine tumor necrosis factor $(m T N F)$ by a 17 -h lactate dehydrogenase release $(B)$ or 3-(4,5-dimethylthiazole-2-yl)-2,5-diphenyltetrazolium bromide reduction $(C)$ assays. The staining and sensitivity of wild-type (WT)-1 (gray) and or CathB ${ }^{-1-}$ iMEFs analyzed in parallel are shown for the comparison. Averages for a triplicate experiment are shown; bars, \pm SD. D. WT- 1 and $\mathrm{CathB}^{-1-}-3$ iMEFs were cotransfected with a $\mathrm{H} 2 \mathrm{~B}-\mathrm{eGFP}$ fusion protein and a retroviral vector encoding for mCathB or an empty vector $54-60 \mathrm{~h}$ before the 12-h treatment with $5 \mu \mathrm{M} \mathrm{CHX}$ alone or with $0.1 \mathrm{ng} / \mathrm{ml}$ mTNF. The percentage of apoptotic cells was determined by counting of the cells with condensed chromatin in eight independent fields. Averages of four $\left(\mathrm{CathB}^{-1-}\right)$ and one (WT) independent experiments are shown; bars, \pm SD. $*, P<0.05$ as analyzed by the two sample two-tailed $t$ test.
A

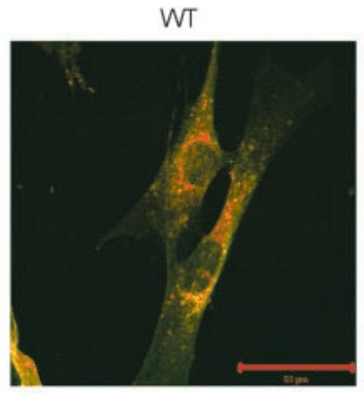

B

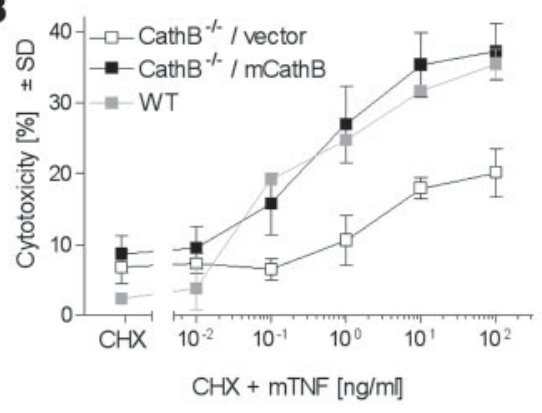

D

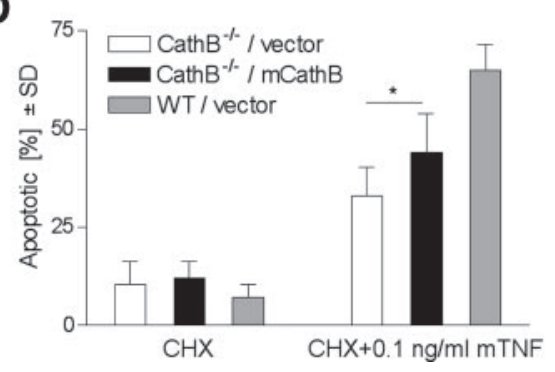

CathB $\%$

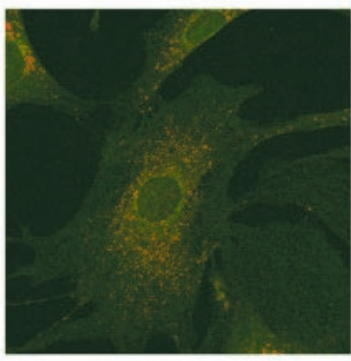

C

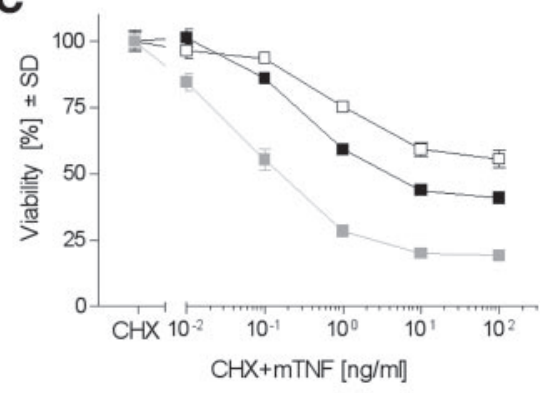


transfection. Transiently transfected cells were left untreated or treated with CHX or TNF plus CHX for $12 \mathrm{~h}$, and the percentage of apoptotic green nuclei of all of the green nuclei was counted. No significant difference in the number of apoptotic cells was observed between vector- and CathB-transfected iMEFs under control- (medium alone) or CHX-treated conditions (Fig. 2D; data not shown). $\mathrm{TNF}$ induced, however, significantly more apoptosis in $\mathrm{CathB}^{-1-}$ iMEFs transfected with CathB than in vector-transfected $\mathrm{CathB}^{-1-}$ iMEFs. The number of apoptotic cells in CathB-transfected iMEFs did not fully reach that of vector-transfected WT iMEFs, but the sensitizing effect of transiently expressed CathB was significant in all of the four independent experiments performed.

To additionally challenge the role of CathB in TNF-induced death of iMEFs, we investigated the effect of the inhibition of CathB activity and expression on the TNF sensitivity of WT iMEFs. The inhibition of cysteine cathepsins by broad spectrum cysteine cathepsin inhibitors, zFA-fmk and ALLN, as well as the inhibition of CathB by a more specific inhibitor, CA-074-Me, protected WT iMEFs significantly against TNF-induced apoptosis-like cell death as measured by counting of apoptotic cells with condensed and fragmented nuclei (Fig. 3A) and LDH release assay (Fig. 3B). The inhibition of caspases and CathD by zVAD-fmk and pepstatin A, respectively, had no protective effect against TNF-induced death of iMEFs (Fig. 3B). On the contrary, zVAD-fmk that inhibits all of the known caspases had a dose-dependent and significant sensitizing effect (Fig. 3B). More specific inhibition of activities of effector caspases and caspase- 8 by DEVD-CHO or DEVD-cmk and IETD-CHO, respectively, had no significant effect on TNF-induced death of iMEFs (Fig. 3C). Also, serine protease (TLCK and TPCK) and calpain (PD1566) inhibitors were without an effect in similar assays (data not shown).

Because the specificity of pharmacological protease inhibitors cannot be fully guaranteed, we also used RNA interference technology to deplete iMEFs of CathB. Despite numerous attempts to optimize the RNA interference conditions, transfection of WT iMEFs with small interfering RNA directed against mCathB resulted only in the partial $(20-30 \%)$ and transient reduction in the total cysteine cathepsin activity and CathB protein level (Fig. 3D). Thus, the total cysteine cathepsin activity remaining in CathB small interfering RNA-transfected WT iMEFs was $>3$ times higher than that in $\mathrm{CathB}^{-1-}$ iMEFs (data not shown). Accordingly, transfection with CathB small interfering RNA protected iMEFs only partially, but significantly, against TNF-induced cytotoxicity (Fig. 3E).

CathB Is Required Neither for TNF Processing nor TNF-Induced Activation of NF- $\mathbf{B}$ and JNK. TNF binds to two cell surface receptors, TNF-R1 and TNF-R2. TNF-R1 is the major mediator of cell death, whereas both receptors can activate NF- $\kappa \mathrm{B}$ and JNKs. To study whether CathB deficiency affected TNF-R1-mediated responses other than cell death, we took advantage of the fact that hTNF has $>100$ times higher affinity to murine TNF-R1 than TNF-R2 (34).

Using a NF- $\kappa$ B reporter assay, we compared the ability of hTNF to activate NF- $\kappa$ B in WT and $\mathrm{CathB}^{-1-}$ iMEFs. A 6-h treatment with 10 $\mathrm{ng} / \mathrm{ml}$ hTNF induced an $\sim 4$-fold activation of NF- $\kappa \mathrm{B}$ in both cell types (Fig. 4A). Also, the rapid TNF-induced activation of JNK (15-30 min after TNF treatment) as monitored by the JNK-in-gelkinase assay was indistinguishable in WT and $\mathrm{CathB}^{-1-}$ iMEFs (Fig. $4 B$ ). Whereas the TNF-induced activation of NF- $\kappa$ B and JNK occur
Fig. 3. Tumor necrosis factor (TNF) induces cathepsin B (CathB)-dependent death in immortalized murine embryonic fibroblasts (iMEFs). $A$, wildtype (WT)-1 iMEFs pretreated for $1.5 \mathrm{~h}$ with vehicle alone (no inh.), $100 \mu \mathrm{M}$ z-Phe-Ala-fluoromethylketone $(z F A-f m k), 20 \mu \mathrm{M}$ CA-074-Me, or $40 \mu \mathrm{M}$ $A L L N$ were treated with $5 \mu \mathrm{M}$ cycloheximide $(C H X)$ alone or with $10 \mathrm{pg} / \mathrm{ml}$ murine tumor necrosis factor $(m T N F)$ for $15 \mathrm{~h}$ before the determination of the percentage of apoptotic cells as described in the legend for Fig. $1 C$. The data for $\mathrm{CathB}^{-1-}-1 \mathrm{iMEFs}$ is shown for comparison. Percentage of apoptotic cells in $\mathrm{CHX}$-treated WT and $\mathrm{CathB}^{-1-} \mathrm{iMEFs}$ was $1.7 \pm 0.9$ and $11.8 \pm 1.9$, respectively. Averages are derived from counting four randomly chosen fields of 60-100 cells/treatment; bars, \pm SD. B, WT-1 iMEFs pretreated for $24 \mathrm{~h}$ or $1.5 \mathrm{~h}$ with indicated concentrations $(\mu \mathrm{M})$ of pepstatin A $(P e p A)$ or other indicated inhibitors, respectively, were treated for $17 \mathrm{~h}$ with $5 \mu \mathrm{M} \mathrm{CHX}+0.1 \mathrm{ng} / \mathrm{ml}$ mTNF. Cell death was evaluated by the lactate dehydrogenase $(\mathrm{LDH})$ release assay. The $\mathrm{LDH}$ release from cells treated with CHX and the various inhibitors was always below 2\% (data not shown) Averages of a triplicate experiment are shown; bars, \pm SD. $C$, WT-1 iMEFs pretreated for $1.5 \mathrm{~h}$ with medium alone (no inh.), $200 \mu \mathrm{M}$ DEVD-CHO, 200 $\mu \mathrm{M} I E T D-C H O$, or $10 \mu \mathrm{M} D E V D-c m k$ were treated and analyzed as described in the legend for Fig. 1C. Percentage of apoptotic cells in CHX-treated WT iMEFs was $2.9 \pm 1.5$. D. WT- 1 iMEFs transfected with $100 \mathrm{~nm}$ mismatch control $(\mathrm{mm})$ or murine CathB $(\mathrm{mCathB})$ small interfering RNA oligos were analyzed for the expression of CathB and Hsp70 (loading control) by immunoblot analysis and for the total cysteine cathepsin activity by determining the cleavage of z-Phe-Arg-7-amino-trifluoromethylcoumarin 50 and $36 \mathrm{~h}$ after the transfection, respectively. $E$, cells from the same transfection were treated for $14 \mathrm{~h}$ with $5 \mu \mathrm{M}$ CHX alone or with mTNF 36-50 h after the transfection, and the cytotoxicity was analyzed by the LDH release assay. $D$ and $E$, averages from a triplicate experiment are shown; bars, \pm SD. The experiments were repeated once $(A)$, twice $(C)$, or three times $(B, D$, and $E)$ with essentially similar results. $*, P<0.05, * *, P<0.01$, and $* * *$, $P<0.001$ as determined by two-tailed $t$ test and compared with WT iMEFs pretreated with vehicle alone $(A-C)$ or cells transfected with $\mathrm{mm}$ small interfering RNA ( $D$ and $E$ ).
A
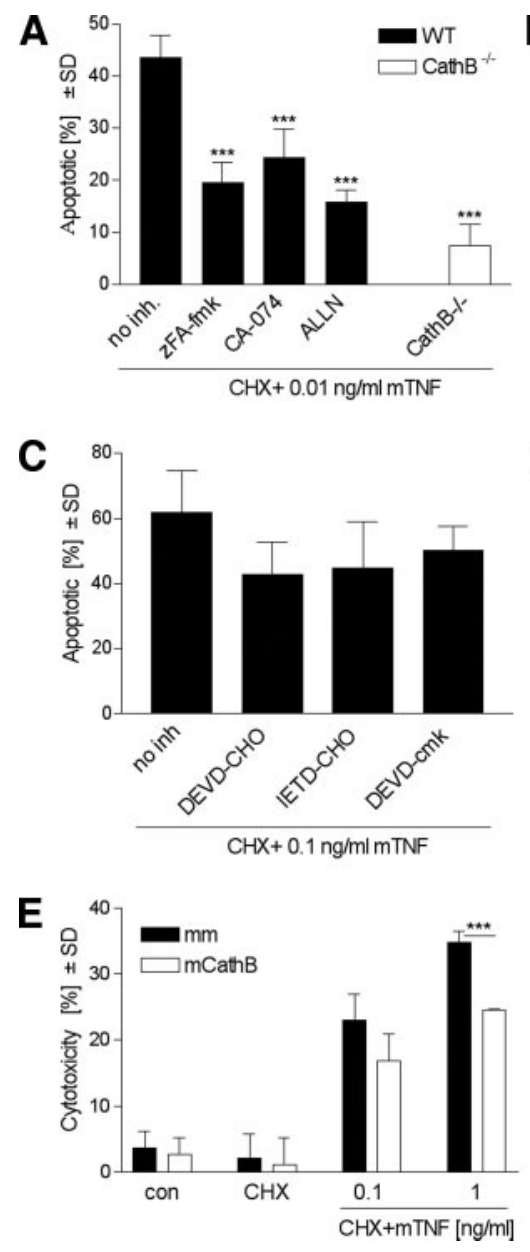

5305
B

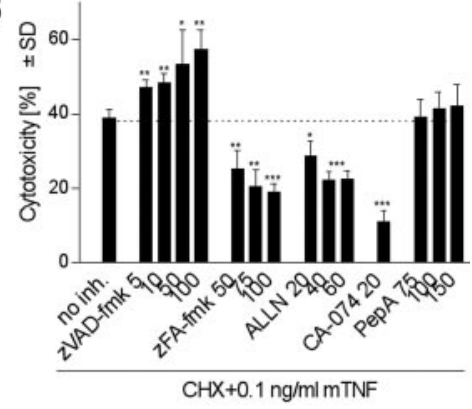

D

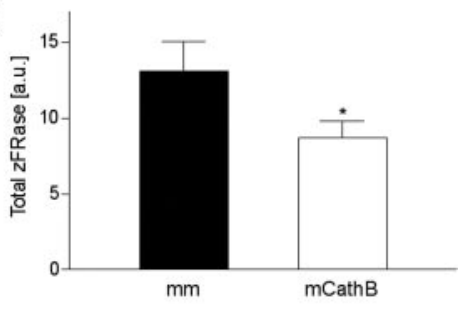

mCathB

Hsp70

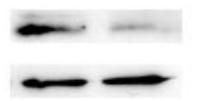




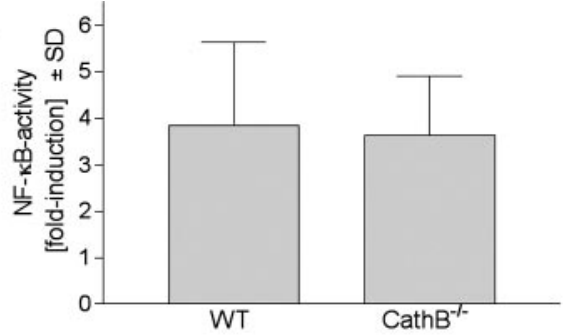

B

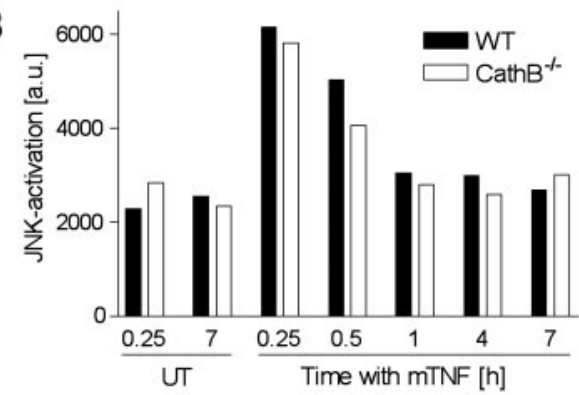

C

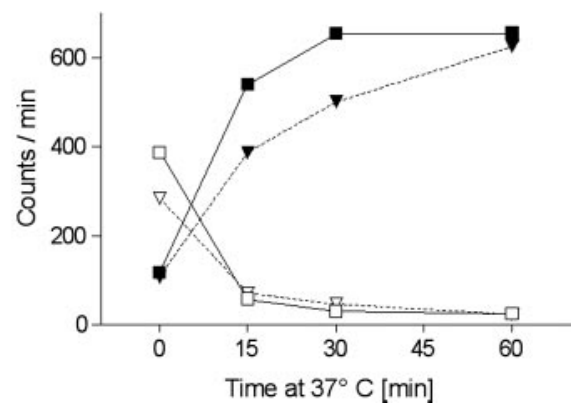

Fig. 4. Cathepsin B $(C a t h B)$ is not required for tumor necrosis factor signaling. $A$, wild-type $(W T)$ and $\mathrm{CathB}^{-/-}$immortalized murine embryonic fibroblasts (iMEFs) transfected with plasmids encoding for nuclear factor $\kappa \mathrm{B}(N F-\kappa B)$-responsive firefly luciferase and constitutively expressed renilla luciferase were left untreated or treated for $6 \mathrm{~h}$ with $10 \mathrm{ng} / \mathrm{ml}$ human tumor necrosis factor. The firefly luciferase activity was determined relative to the renilla luciferase activity, and the NF- $\kappa \mathrm{B}$ activity is expressed as fold induction on tumor necrosis factor-treatment. Averages from nine (WT; pooled from WT-1 and -3) or six (CathB ${ }^{-1-}$; pooled from $\mathrm{CathB}^{-/-}-1$ and -2) quadruplicate experiments are shown; bars, \pm SD. $B$, c-Jun $\mathrm{NH}_{2}$-terminal kinase $(J N K)$ activity was measured by the JNK-in-gel-kinase assay in WT-1 and CathB ${ }^{-1-}-2$ iMEFs left untreated (UT) or treated with $1 \mathrm{ng} / \mathrm{ml}$ murine tumor necrosis factor $(m T N F)$ for indicated times. The experiment was repeated three times with essentially similar results. C, WT-1 (squares) and $\mathrm{CathB}^{-1-}-2$ (triangles) iMEFs were prelabeled with $\left.{ }^{125} \mathrm{I}\right]$ human tumor necrosis factor at $0^{\circ} \mathrm{C}$. The amount of ${ }^{125} \mathrm{I}$-human tumor necrosis factor (counts $/ \mathrm{min}$ ) bound to the plasma membrane receptor (open symbols) or degraded (closed symbols) after indicated times after transfer to $37^{\circ} \mathrm{C}$ are shown. The experiment was repeated twice with essentially similar results.

rapidly after the binding of TNF to its receptor at the plasma membrane, the signaling to death requires the internalization and reorganization of the receptor complex in the endosomal-lysosomal compartment (35). Therefore, we next investigated whether CathB was required for the internalization and lysosomal processing of TNF. For this purpose, cells prelabeled with $\left[{ }^{125} \mathrm{I}\right] \mathrm{hTNF}$ at $0^{\circ} \mathrm{C}$ were transferred to $37^{\circ} \mathrm{C}$, and the amount of receptor-bound and degraded TNF were analyzed at $15 \mathrm{~min}$ intervals until all of the TNF was processed at 60 min. Although the degradation of TNF in $\mathrm{CathB}^{-1-}$ iMEFs was slightly slower than in WT cells, no significant differences in the amounts of receptor-bound and degraded TNF were observed between the two genotypes (Fig. 4C).

CathB Is Required for the TNF-Induced Lysosomal Membrane Permeabilization, Cytochrome $c$ Release, and Effector Caspase Activation in iMEFs. To study at which level of the death signaling cascade CathB functions, we compared the ability of TNF plus CHX to trigger lysosomal membrane permeabilization, cytochrome $c$ re- lease, and effector caspase activation in WT and $\mathrm{CathB}^{-/-}$iMEFs. An 8-h treatment of WT iMEFs with TNF plus CHX resulted in an $>10$-fold increase in the amount of active cysteine cathepsins in the cytosol, the cytosolic cathepsin activity of treated cells corresponding to $>20 \%$ of the total cellular activity (Fig. $5 A$ ). The total cysteine cathepsin activity in $\mathrm{CathB}^{-/-}$iMEFs was only $\sim 15 \%$ of that in the WT cells, indicating that CathB is responsible for $>80 \%$ of the total cysteine cathepsin activity in iMEFs. No significant increase in the cytosolic cysteine cathepsin activity was detected after TNF plus CHX treatment in $\mathrm{CathB}^{-1-}$ iMEFs (Fig. $5 A$ ).

Next, we studied whether CathB is required for TNF plus CHXinduced cytochrome $c$ release and effector caspase activation by immunocytochemistry and enzyme activity measurement, respectively. Treatment of WT iMEFs with TNF plus CHX for $8 \mathrm{~h}$ resulted in the strong increase in caspase-3-like protease activity (DEVDase) in WT iMEFs, whereas the activity in similarly treated $\mathrm{CathB}^{-1-}$ iMEFs resembled that in the CHX-treated cells (Fig. 5B). Accordingly, TNF plus CHX induced the release of cytochrome $c$ from the mitochondrial network into the cytoplasm in approximately half of the iMEFs analyzed, whereas $<5 \%$ of the $\mathrm{CathB}^{-/-}$iMEFs had cytochrome $c$ localized in the cytosol (Fig. 5C). The cytochrome $c$ release in WT iMEFs is a conservative estimate, possibly underestimating the real release, because dying WT iMEFs detached from the dish during the TNF treatment, thereby decreasing the amount of cells with released cytochrome $c$.

To determine whether CathB plays a role in other death-pathways than that induced by TNF plus CHX, we stimulated WT and CathB $^{-1-}$ iMEFs with Fas ligand and staurosporine, two stimuli reported to induce the lysosomal membrane permeabilization in target cells $(19,20)$. CathB ${ }^{-1-}$ iMEFs were significantly protected against cytotoxicity induced by Fas ligand, although the effect was not as pronounced as in the case of TNF (Fig. 5D). In the case of staurosporine, no significant difference in the cell death was observed between WT and $\mathrm{CathB}^{-1-}$ iMEFs (Fig. 5D). To test whether other cathepsins could be involved in this death process, we compared the sensitivity of WT, CathB ${ }^{-/-}, \mathrm{CathL}^{-1-}$, and $\mathrm{CathD}^{-1-}$ iMEFs to staurosporine. CathD ${ }^{-1-} \mathrm{iMEFs}$ displayed significant resistance to staurosporine-induced cell death (Fig. 5E).

Transformation by v-Ha-ras or c-src Sensitizes NIH3T3 Cells to TNF-Induced Cysteine Cathepsin-Dependent PCD. To test whether oncogene-mediated transformation would affect the lysosomal death pathway, we transformed iMEFs (NIH3T3) with oncogenic v-Ha-ras or c-srcY527F. As a control, we used NIH3T3 cells transduced with vector alone or with SV40 large T antigen. The successful transformation of Ras- and Src-transduced cells was verified by the evaluation of the morphology by phase contrast microscopy (Fig. 6A) and foci formation assay (data not shown). SV40-LT-transduced cells had a tendency to transform spontaneously after several passages, but all of the experiments using these cells were done before any signs of transformation. Ras- and Src-mediated transformation was associated with massive increase in the expression levels of CathB and CathL and approximately a doubling in the total cellular cysteine cathepsin activity (Fig. 6B). Ras- and Src-transduced cells were also significantly sensitized to the death induced by TNF plus CHX as measured by LDH or MTT assay, whereas SV40-LT-transduced cells displayed a similar TNF sensitivity as vector-transduced control cells (Fig. 6C; data not shown). Taken together with the fact that 3T3-immortalized MEFs were $\sim 100$-fold more sensitive to TNF plus CHX than any of the primary MEFs used in this study (Fig. $1 A$; Table 1), both immortalization and transformation appear to contribute to the sensitization of fibroblasts to the CathB-dependent death-pathway.

Next, we tested whether the cysteine cathepsin-dependent death pathway contributes to the transformation-associated sensitization of NIH3T3 cells to TNF. Indeed, the treatment with TNF plus CHX resulted in 
A

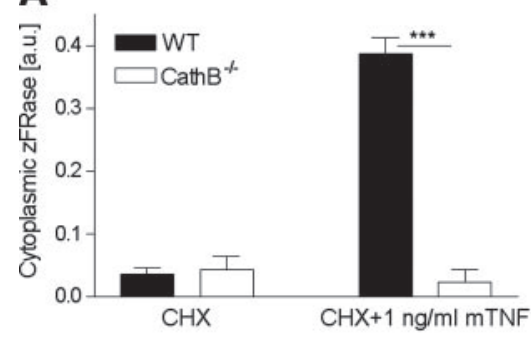

C

Fig. 5. Cathepsin B $(C a t h B)$ is an upstream effector in tumor necrosis factor-induced death signaling and participates also in Fas ligand (FasL)induced death. $A-C$, wild-type $(W T)$ and $\mathrm{CathB}^{-1-}$ immortalized murine embryonic fibroblasts (iMEFs) were treated for $8 \mathrm{~h}$ with $5 \mu \mathrm{M}$ cycloheximide $(\mathrm{CHX})$ alone or with $1 \mathrm{ng} / \mathrm{ml}$ murine tumor necrosis factor $(m T N F)$ and analyzed for the cytosolic cysteine cathepsin activity by the zFRase assay $(A)$, total caspase-3-like activity by the DEVDase assay $(B)$, and the localization of cytochrome $c$ and the nuclear morphology by immunostaining and ethidum-bromide, respectively $(C)$. Averages of a representative triplicate experiment $(A$ and $B$ ) and representative images with $50-\mu \mathrm{m}$ size bars $(C)$ of a minimum of three similar experiments are shown; bars, \pm SD. D, WT- $1 / 3$ and $\mathrm{CathB}^{-1-}-1 / 2$ iMEFs were treated with $1 \mathrm{ng} / \mathrm{ml} \mathrm{mTNF}+5 \mu \mathrm{M} \mathrm{CHX}$ or $10 \%$ FasL-supernatant $+1 \mu \mathrm{M}$ CHX for $17 \mathrm{~h}$ or with $100 \mathrm{~nm}$ staurosporine (STS) for $48 \mathrm{~h}$. The cytotoxicity was determined by the lactate dehydrogenase release assay. Averages for two independent triplicate experiments are shown; bars, \pm SD. Essentially similar results were obtained in several repetitions with different WT and $\mathrm{CathB}^{-1-}$ iMEF lines. $E$, WT-2, CathB ${ }^{-1-}-2$, $\mathrm{CathL}^{-1-}$, and $\mathrm{CathD}^{-1-}$ iMEFs were treated with $100 \mathrm{nM}$ STS for $24 \mathrm{~h}$. The viability was determined by the 3-(4,5-dimethylthiazole-2-yl)-2,5diphenyltetrazolium bromide reduction assay as percent of vehicletreated control cells. Averages for three independent triplicate experiments are shown; bars, \pm SD. $* * *, P<0.001$ as determined by two-tailed $t$ test and compared with STS-treated WT iMEFs.
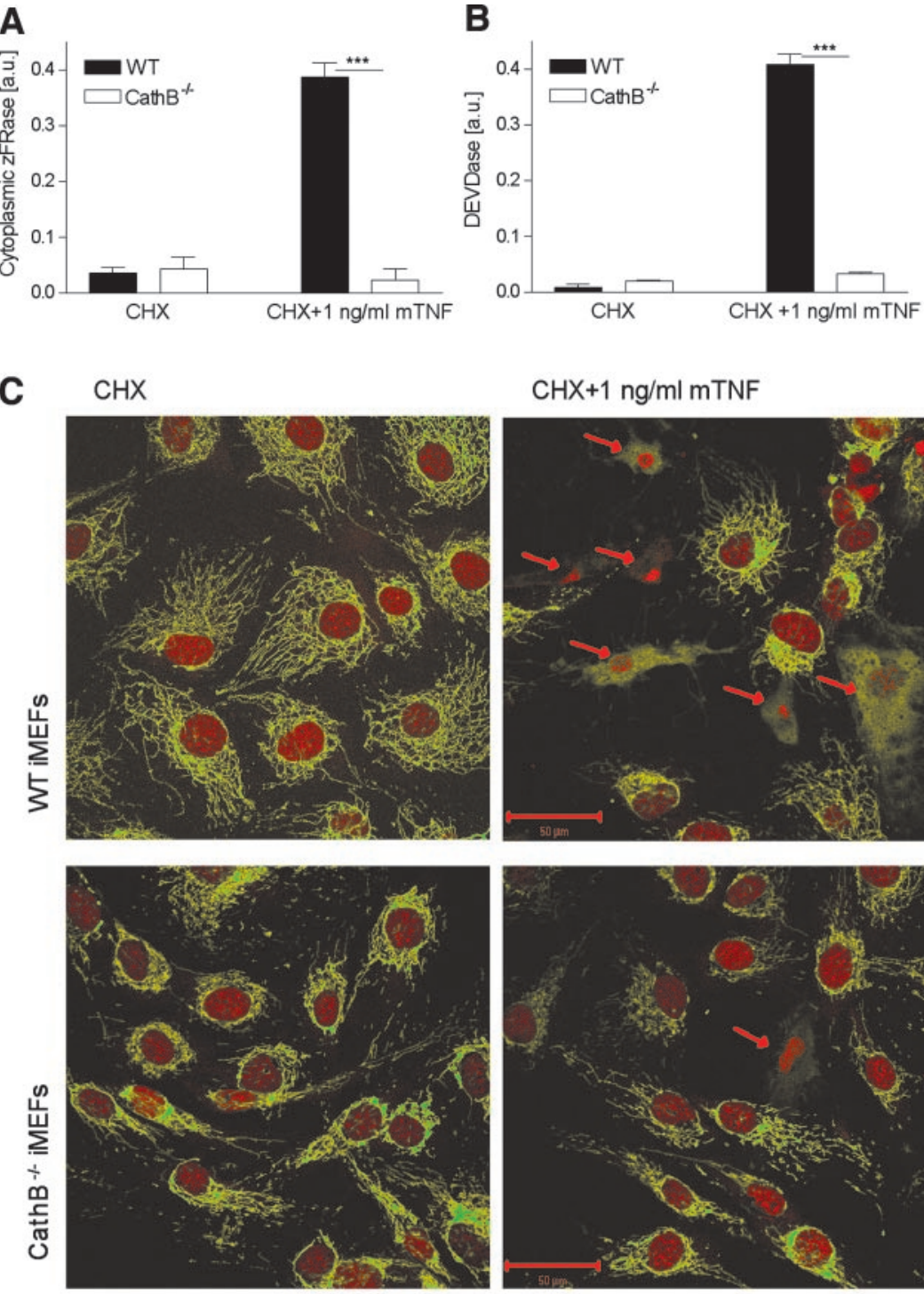

\section{$\mathrm{CHX}+1 \mathrm{ng} / \mathrm{ml} \mathrm{mTNF}$}

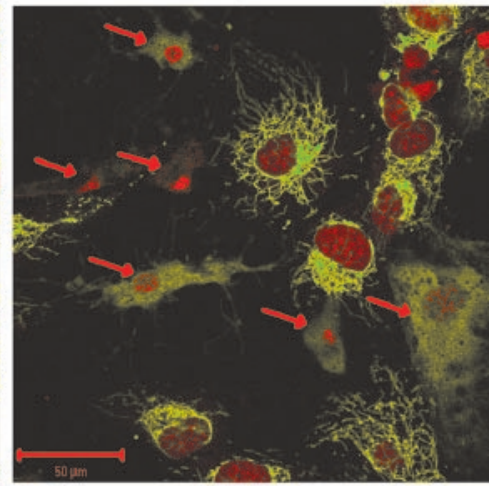

D

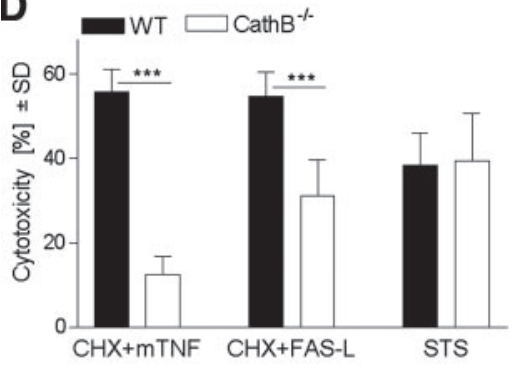

E

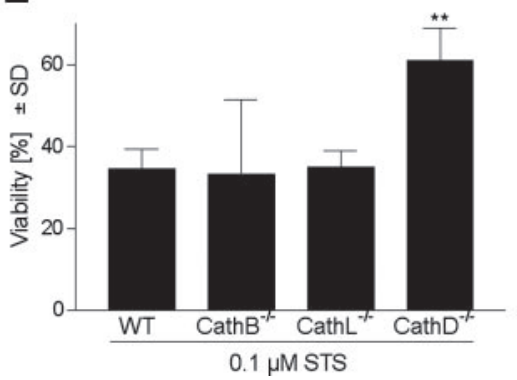

$>3$-fold higher cytosolic cysteine cathepsin activity in Ras-transformed cells than in control cells (Fig. 6D), and the inhibitors of cysteine cathepsins (CA-074-Me and ALLN) effectively rescued Ras-transformed cells from the cytotoxicity induced by TNF plus CHX (Fig. 6E). Similar to the iMEFs (Fig. 3A), caspase inhibition by zVAD-fmk did not rescue the cells from TNF. On the contrary, zVAD-fmk additionally sensitized the cells to TNF plus CHX (Fig. $6 F$ ).

\section{DISCUSSION}

Most cancer-associated growth promoting signals are directly coupled to increased cell death, and, therefore, they promote tumor growth only when cooperating with antiapoptotic mechanisms (24). For example, proliferative responses induced by c-Myc oncoprotein or the loss of retinoblastoma tumor suppressor protein result in a deregulated cell cycle and sustained activation of E2F-1 that, in addition to increased cell division, triggers caspase activation and apoptosis (36, 37). Although the promotion of growth, survival, and motility are the prominent functions of oncoproteins of Ras and Src families, they also carry the ability to sensitize cells to cell death induced by numerous stimuli including TNF $(38,39)$ and various anticancer drugs $(40-42)$. In this report, we demonstrate that the sensitization of fibroblasts to TNF-mediated death on spontaneous immortalization as well as Ras- 
A

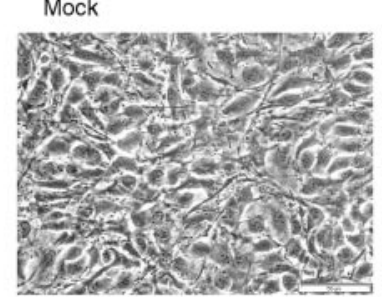

$v$-Ha-ras

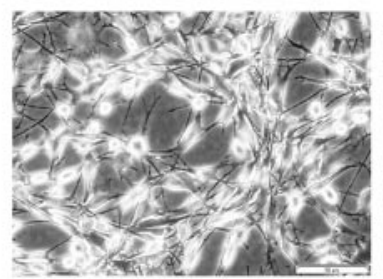

SV $40-L T$

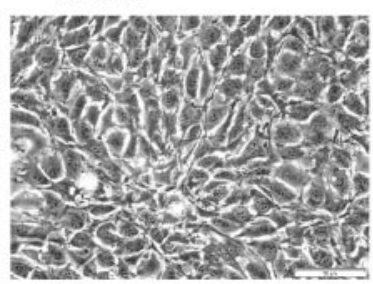

c-srcY527F

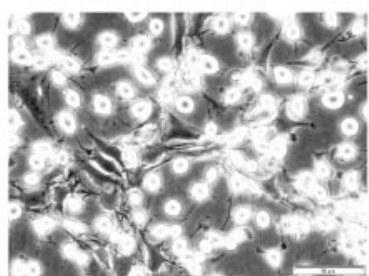

B

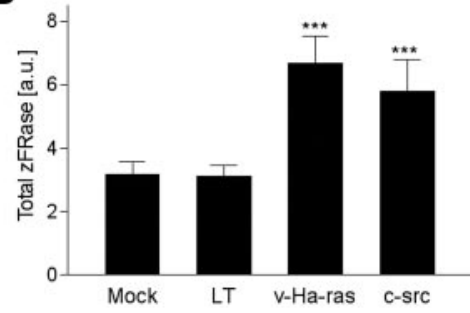

CathB

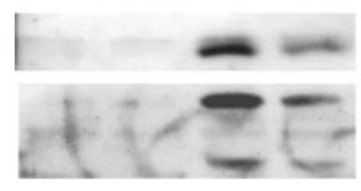

$\mathrm{GAPDH}=\mathrm{m}$
C

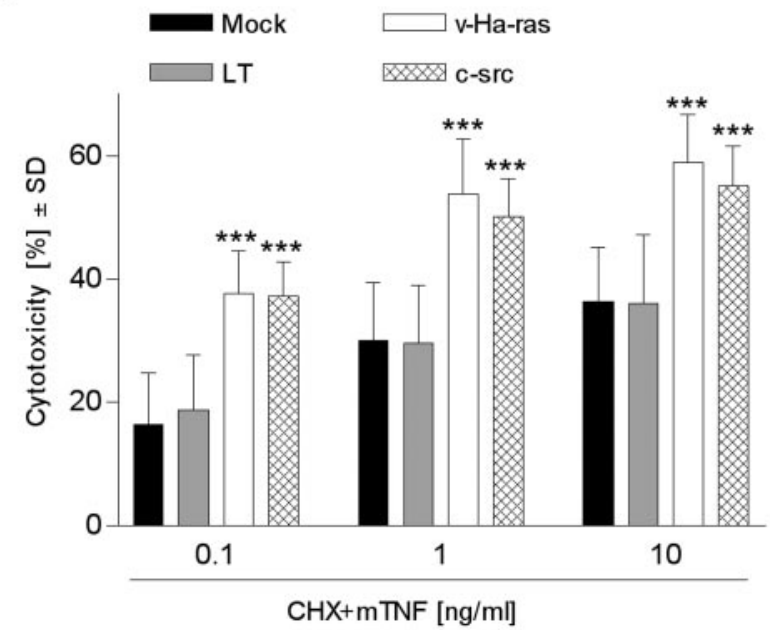

D

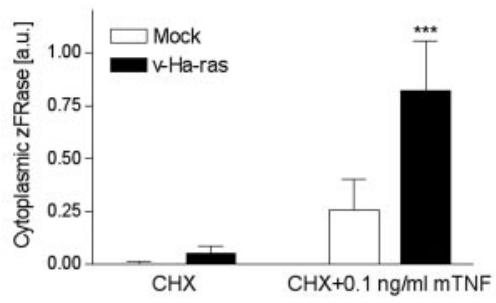

E

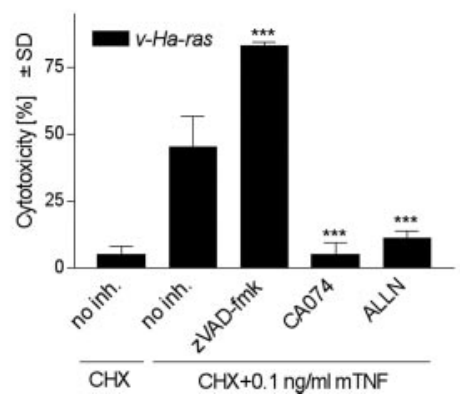

Fig. 6. Transformation of NIH3T3s with oncogenic ras and src up-regulates cysteine cathepsins and sensitizes cells to tumor necrosis factor. $A$, phase contrast pictures of vector-,

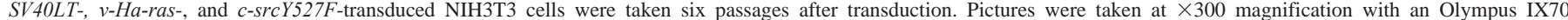

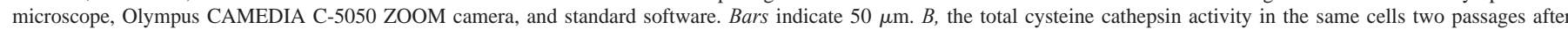

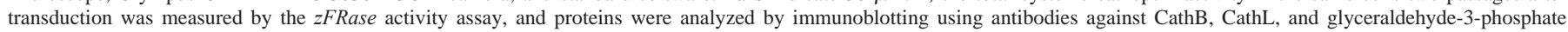

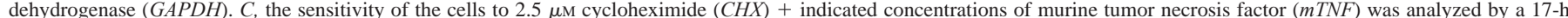

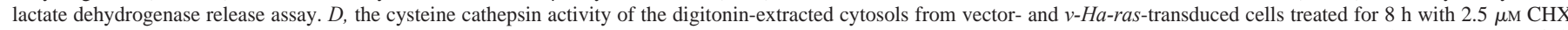

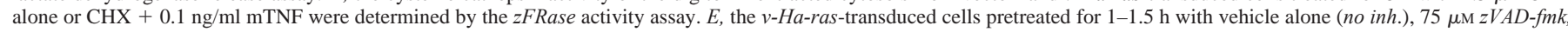

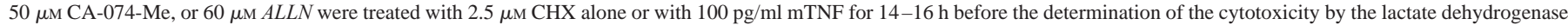

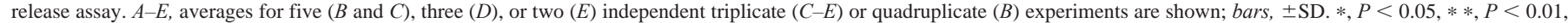

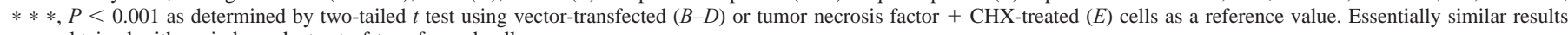
were obtained with an independent set of transformed cells.

and Src-induced transformation depends on cysteine cathepsins, particularly CathB. This conclusion is based on the strong experimental evidence showing that whereas spontaneous immortalization sensitizes WT MEFs to TNF-induced cell death >1000-fold, it completely fails to sensitize MEFs deficient for CathB. Several lines of argumentation support the idea that the resistant phenotype of $\mathrm{CathB}^{-/-}$ iMEFs is because of the direct role of this cysteine protease in the TNF-induced death rather than variations in the immortalization process per se or other unspecific differences between WT and $\mathrm{CathB}^{-1-}$ iMEFs. First, the sequence specific depletion of CathB by RNA interference as well as several pharmacological cysteine cathepsin inhibitors prevented TNF-induced death of immortalized WT cells. Second, ectopic CathB rapidly sensitized resistant $\mathrm{CathB}^{-1-}$ iMEFs to TNF-induced cell death. Third, binding, internalization and degradation of TNF as well as TNF-induced activation of NF- $\kappa \mathrm{B}$ and JNK were not altered in $\mathrm{CathB}^{-1-}$ iMEFs. Fourth, $\mathrm{CathB}^{-1-}$ iMEFs were not generally unable to die, because they were killed as effectively as WT cells by staurosporine. Fifth, the lack of immortalization-associated sensitization to TNF was evident in four independent $\mathrm{CathB}^{-1-}$ iMEF lines. And finally, differences concerning the growth rate and morphology (data not shown), ploidy, p53 mutations, and p19 ${ }^{\text {Arf }}$ status could not explain the TNF resistance of $\mathrm{CathB}^{-/-}$iMEFs.

The cysteine cathepsin family consists of at least 11 closely related members, some of which have been recently assigned specific functions, for example, in bone remodeling, hair follicle morphogenesis, and antigen presentation (reviewed in Ref. 43). Thus, the CathB dependence of TNF-induced death of iMEFs could reflect either a unique role for this particular cysteine cathepsin in the death process or a reduced total cysteine cathepsin activity in these cells. Also, our data showing that iMEFs lacking another cysteine cathepsin, CathL, failed to get fully sensitized to TNF-induced cell death on immortalization support the latter hypothesis. Accordingly, the dramatic effect 
of CathB deficiency and the significant but lesser effect of CathL deficiency could be explained by the data showing that in iMEFs, CathB and CathL contribute to up to $80 \%$ and $20 \%$ of the total cysteine cathepsin activity, respectively (data not shown). Furthermore, the sensitization of iMEFs to TNF-induced cysteine cathepsindependent death by Src- and Ras-induced transformation was associated with dramatic increase in the expression levels of both CathB and CathL. The expression of other cathepsins was not analyzed in this study, but it should be noted that human tumors have been reported to have increased levels and changed trafficking of several cysteine cathepsins (44) as well as an aspartyl cathepsin, CathD (45). CathD has also been implicated in the TNF-induced death of human cervix carcinoma cells (11). Our experiments using CathD-deficient cells as well as pharmacological inhibition of CathD activity by pepstatin A in WT cells argue, however, against a prominent role for CathD in TNF-induced death pathway in iMEFs. CathD was, however, required for efficient killing of iMEFs by staurosporine. In agreement with these data, TNF-induced death of transformed human skin fibroblasts does not depend on CathD, whereas human fibroblasts from individuals with I cell disease (characterized by impaired lysosomal function and very low levels of CathB and L) are highly TNF resistant (46). Furthermore, staurosporine-induced cell death in T cells (20) as well as in human fibroblasts (47) requires CathD rather than cysteine cathepsin activity. Taken together these data suggest that even in same cells, different death stimuli can trigger death pathways dependent on either aspartyl or cysteine cathepsins.

Although the classic caspase-dependent apoptosis pathway appears to be the major death signaling route activated by TNF in primary cells $(7,48)$, cysteine cathepsin have been suggested to co-operate with caspases in the execution process also in primary cells by enhancing the release of cytochrome $c$ from the mitochondrial intermembrane space into the cytosol $(15,16)$. TNF-treated CathB ${ }^{-1-}$ iMEFs showed significantly reduced release of cytochrome $c$, indicating that $\mathrm{CathB}$ functions upstream of mitochondria also in immortalized cells. The TNF-induced death of iMEFs differs, however, essentially from that of primary cells in regard to the role of caspases. The activation of effector caspases in immortalized cells did not appear to contribute to the death signaling cascade, because the deficiency of the major effector caspase, caspase-3, as well as the inhibition of caspases by various pharmacological inhibitors rather sensitized than protected iMEFs against TNF-induced death. These data are in concordance with earlier observations demonstrating that TNF-induced death of immortalized or transformed fibroblasts is either unaffected or enhanced by genetic and pharmacological inhibition of caspases $(6,49)$.

Spontaneous immortalization of murine fibroblasts occurs via the loss of p53 activity either through the mutation in the $p 53$ gene or the loss of the Ink4a-Arf gene locus (33). The Ink4a-Arf locus encodes two proteins, $\mathrm{p} 16^{\mathrm{Ink} 4 \mathrm{a}}$ and $\mathrm{p} 19^{\mathrm{Arf}}$, that restrain cell growth by affecting the functions of the retinoblastoma protein and p53, respectively. Thus, the loss of this locus results in the deregulated activation of E2F-1, which in turn could result in the apoptosis-prone phenotype as described previously. The sensitization of MEFs to the TNF-induced CathB-mediated cell death on immortalization is, however, unlikely to depend on the loss of the Ink4a-Arf gene locus, because WT iMEFs with or without this locus (as analyzed by the expression of p19 Arf displayed indistinguishable TNF-sensitive phenotypes. Whether the loss of p53 activity is required for the sensitization remains to be studied. The tumor suppressor proteins $\mathrm{p} 16^{\text {Ink4a }}, \mathrm{p} 14^{\text {Arf }}$ (the human homologue of murine p19 ${ }^{\mathrm{Arf}}$ ), and p53 are commonly mutated in human cancers, and, therefore, the events of immortalization of MEFs and transformation of human cells share major characteristics. Contrary to the transformed cells, iMEFs did not have increased levels of cysteine cathepsins, and yet the immortalization significantly increased the TNF-induced permeabilization of lysosomes (Ref. 16; data not shown). Thus, the sensitization is more likely to occur at the level of the yet uncovered signaling pathway upstream of the lysosomal membrane permeabilization or via changes in the stability of lysosomal membranes. A similar shift from caspase- to cathepsindependent cell death has been reported in TNF-treated vascular endothelial cells after inhibition of phosphoinositol-3'-kinase (50), an enzyme that, among several other functions, is known to control the maturation, size, and activity of lysosomes (51). Thus, it is interesting to note that the volume of individual lysosomes as well as the total lysosomal compartment grow during replicative aging of fibroblasts, and larger lysosomes have been suggested to be more susceptibility to rupture than small lysosomes (52). Alternatively, the probability of lysosomal leakage can also be enhanced because of increased protein turnover in rapidly growing cells. The turnover of iron-containing proteins leads to lysosomal accumulation of iron that via Fenton chemistry can lead to increased oxidative stress and destabilization of lysosomal membranes (13). The role of increased lysosomal size and iron as sensitizers of immortalized and/or transformed cells to the lysosomal death pathway needs, however, to be carefully tested.

The data presented above shows for the first time that in addition to sensitizing cells to classic apoptosis, tumorigenesis also lowers the threshold to the lysosomal death pathway. Thus, it is tempting to speculate that the activation of death pathways dependent on cysteine cathepsins could prove useful in cancer therapy. Conversely, tumors that manage to suppress the alternative death programs might have a selective growth advantage. Indeed, tumor progression is associated with several changes that confer resistance to the lysosomal cysteine cathepsin-mediated death pathway, i.e., activation of $\mathrm{NF}-\kappa \mathrm{B}$ that induces the expression of potent cytosolic serine and cysteine protease inhibitor SpiA2 (53), increased activity of phosphoinositol-3'-kinase that protects cells from cathepsin-mediated death (50), increased expression of endogenous cysteine cathepsin inhibitors (54), and translocation of the heat shock protein 70 to the membranes of a subpopulation of tumor cell lysosomes, where it stabilizes them and thereby inhibits lysosomal membrane permeabilization (55). Taken together, lysosomes and the control of their stability are affected in multiple ways during tumorigenesis. The future research on the nature of the signals that lead to cancer-specific permeabilization of lysosomes as well as mechanisms cancer cells use to inhibit lysosomal permeabilization will hopefully open new possibilities to develop anticancer drugs that target tumor cell lysosomes.

\section{ACKNOWLEDGMENTS}

We thank Karina Grøn Henriksen for excellent technical assistance, Peter Saftig, Christoph Peters, Stephane Hunot, Richard Flavell, Anthony Cerami, Christian Holmberg, Nikolaj Dietrich, Boris Margulis, Jennifer Rohn, and Sarah Courtneidge for invaluable reagents, and Anja Groth for helpful discussions.

\section{REFERENCES}

1. Strasser A, O'Connor L, Dixit VM. Apoptosis signaling. Annu Rev Biochem 2000; 69:217-45.

2. Leist M, Jäättelä M. Four deaths and a funeral: from caspases to alternative mechanisms. Nat Rev Mol Cell Biol 2001;2:589-98.

3. Ferri KR, Kroemer G. Organelle-specific initiation of cell death pathways. Nat Cell Biol 2001;3:E255-63.

4. Denecker G, Vercammen D, Steemans M, et al. Death receptor-induced apoptotic and necrotic cell death: differential role of caspases and mitochondria. Cell Death Differ 2001;8:829-40.

5. Jäättelä M, Tschopp J. Caspase-independent cell death in T lymphocytes. Nat Immunol 2003;4:416-23.

6. Vercammen D, Beyaert R, Denecker G, et al. Inhibition of caspases increases the sensitivity of L929 cells to necrosis mediated by tumor necrosis factor. J Exp Med 1998; 187:1477-85. 
7. Foghsgaard L, Wissing D, Mauch D, et al. Cathepsin B acts as a dominant execution protease in tumor cell apoptosis induced by tumor necrosis factor. J Cell Biol 2001;153:999-1009.

8. Holler N, Zaru R, Micheau O, et al. Fas triggers an alternative, caspase-8-independent cell death pathway using the kinase RIP as effector molecule. Nat Immunol 2000;1: 489-95.

9. Khwaja A, Tatton L. Resistance to the cytotoxic effects of tumor necrosis factor alpha can be overcome by inhibition of a FADD/caspase-dependent signaling pathway. J Biol Chem 1999;274:36817-23.

10. Leist M, Single B, Castoldi AF, Kuhnle S, Nicotera P. Intracellular adenosine triphosphate (ATP) concentration: a switch in the decision between apoptosis and necrosis. J Exp Med 1997; 185:1481-6.

11. Deiss LP, Galinka H, Berissi H, Cohen O, Kimchi A. Catepsin D protease mediates programmed cell death induced by interferon- $\gamma$, Fas/APO-1 and TNF-alpha. EMBO J 1996;15:3861-70.

12. Gewies A, Grimm S. Cathepsin-B and cathepsin-L expression levels do not correlate with sensitivity of tumor cells to TNF-alpha-mediated apoptosis. Br J Cancer 2003; 89:1574-80.

13. Brunk UT, Neuzil J, Eaton JW. Lysosomal involvement in apoptosis. Redox Rep 2001;6:91-7.

14. Turk B, Stoka V, Rozman-Pungercar J, et al. Apoptotic pathways: involvement of lysosomal proteases. Biol Chem 2002;383:1035-44

15. Guicciardi ME, Deussing J, Miyoshi H, et al. Cathepsin B contributes to TNF-alphamediated hepatocyte apoptosis by promoting mitochondrial release of cytochrome $\mathrm{c}$. J Clin Investig 2000;106:1127-37.

16. Dietrich N, Thastrup J, Holmberg C, et al. JNK2 mediates TNF-induced cell death in mouse embryonic fibroblasts via regulation of both caspase and cathepsin protease pathways. Cell Death Differ 2003;11:301-13.

17. Yuan XM, Li W, Dalen H, et al. Lysosomal destabilization in p53-induced apoptosis. Proc Natl Acad Sci USA 2002;99:6286-91

18. Broker LE, Huisman C, Span SW, et al. Cathepsin B mediates caspase-independen cell death induced by microtubule stabilizing agents in non-small cell lung cancer cells. Cancer Res 2004;64:27-30.

19. Brunk UT, Svensson I. Oxidative stress, growth factor starvation and Fas activation may all cause apoptosis through lysosomal leak. Redox Rep 1999;4:3-11.

20. Bidere N, Lorenzo HK, Carmona S, et al. Cathepsin D triggers Bax activation, resulting in selective AIF relocation in T lymphocytes entering the early commitment phase to apoptosis. J Biol Chem 2003;278:31401-11.

21. Vancompernolle K, Van Herreweghe F, Pynaert G, et al. Atractyloside-induced release of cathepsin $\mathrm{B}$, a protease with caspase-processing activity. FEBS Lett 1998;438:150-8.

22. Boya P, Andreau K, Poncet D, et al. Lysosomal membrane permeabilization induces cell death in a mitochondrion-dependent fashion. J Exp Med 2003;197:1323-34.

23. Cirman T, Oresic K, Droga Mazovec G, et al. Selective disruption of lysosomes in HeLa cells triggers apoptosis, mediated by cleavage of Bid by multiple papain-like lysosomal cathepsins. J Biol Chem 2003;279:3578-87.

24. Hanahan D, Weinberg RA. The hallmarks of cancer. Cell 2000;100:57-70.

25. Deussing J, Roth W, Saftig P, et al. Cathepsins B and D are dispensable for major histocompatibility complex class II-mediated antigen presentation. Proc Natl Acad Sci USA 1998;95:4516-21.

26. Kuida K, Zheng TS, Na S, et al. Decreased apoptosis in the brain and premature lethality in CPP32-deficient mice. Nature (Lond) 1996;384:368-72.

27. Tsujimoto M, Yip YK, Vilcek J. Tumor necrosis factor: specific binding and internalization in sensitive and resistant cells. Proc Natl Acad Sci USA 1985;82:7626-30.

28. Saksela K, Baltimore D. Negative regulation of immunoglobulin kappa light-chain gene transcription by a short sequence homologous to the murine B1 repetitive element. Mol Cell Biol 1993;13:3698-705.

29. Kallunki T, Su B, Tsigelny I, et al. JNK2 contains a specificity-determining region responsible for efficient c-Jun binding and phosphorylation. Genes Dev 1994;8: 2996-3007.

30. Kmiecik TE, Shalloway D. Activation and suppression of pp60c-src transforming ability by mutation of its primary sites of tyrosine phosphorylation. Cell 1987;49: $65-73$.
31. Pear WS, Nolan GP, Scott ML, Baltimore D. Production of high-titer helper-free retroviruses by transient transfection. Proc Natl Acad Sci USA 1993;90:8392-6.

32. Ekdahl CT, Mohapel P, Weber E, et al. Caspase-mediated death of newly formed neurons in the adult rat dentate gyrus following status epilepticus. Eur J Neurosci 2002;16:1463-71.

33. Lowe SW, Sherr CJ. Tumor suppression by Ink4a-Arf: progress and puzzles. Curr Opin Genet Dev 2003;13:77-83.

34. Brouckaert P, Libert C, Everaerdt B, et al. Tumor necrosis factor, its receptors and the connection with interleukin 1 and interleukin 6. Immunobiology 1993;187:317-29.

35. Schutze S, Machleidt T, Adam D, et al. Inhibition of receptor internalization by monodansylcadaverine selectively blocks p55 tumor necrosis factor receptor death domain signaling. J Biol Chem 1999;274:10203-12.

36. Evan GI, Wyllie AH, Gilbert CS, et al. Induction of apoptosis in fibroblasts by c-myc protein. Cell 1992;69:119-28.

37. Wu X, Levine AJ. p53 and E2F-1 cooperate to mediate apoptosis. Proc Natl Acad Sci USA 1994;91:3602-6

38. Fernandez A, Marin MC, McDonnell T, Ananthaswamy HN. Differential sensitivity of normal and Ha-ras-transformed $\mathrm{C} 3 \mathrm{H}$ mouse embryo fibroblasts to tumor necrosis factor: induction of bcl-2, c-myc, and manganese superoxide dismutase in resistant cells. Oncogene 1994;9:2009-17.

39. Chang MY, Won SJ, Yang BC, Jan MS, Liu HS. Selective activation of Ha-ras(val12) oncogene increases susceptibility of NIH/3T3 cells to TNF-alpha. Exp Cell Res 1999;248:589-98.

40. Tanaka N, Ishihara M, Kitagawa M, et al. Cellular commitment to oncogene-induced transformation or apoptosis is dependent on the transcription factor IRF-1. Cell 1994;77:829-39.

41. Basu A, Cline JS. Oncogenic transformation alters cisplatin-induced apoptosis in rat embryo fibroblasts. Int J Cancer 1995;63:597-603.

42. Chen G, Shu J, Stacey DW. Oncogenic transformation potentiates apoptosis, S-phase arrest and stress-kinase activation by etoposide. Oncogene 1997;15:1643-51.

43. Reinheckel T, Deussing J, Roth W, Peters C. Towards specific functions of lysosomal cysteine peptidases: phenotypes of mice deficient for cathepsin B or cathepsin L. Bio Chem 2001;382:735-41.

44. Kos J, Lah TT. Cysteine proteinases and their endogenous inhibitors: target proteins for prognosis, diagnosis and therapy in cancer [review]. Oncol Rep 1998;5:1349-61.

45. Rochefort H, Chalbos D, Cunat S, et al. Estrogen regulated proteases and antiproteases in ovarian and breast cancer cells. J Steroid Biochem Mol Biol 2001;76:11924.

46. Tardy C, Tyynela J, Hasilik A, Levade T, Andrieu-Abadie N. Stress-induced apoptosis is impaired in cells with a lysosomal targeting defect but is not affected in cells synthesizing a catalytically inactive cathepsin D. Cell Death Differ 2003;10:1090100

47. Johansson AC, Steen H, Ollinger K, Roberg K. Cathepsin D mediates cytochrome release and caspase activation in human fibroblast apoptosis induced by staurosporine. Cell Death Differ 2003;10:1253-9.

48. Varfolomeev EE, Schuchmann M, Luria V, et al. Targeted disruption of the mouse Caspase 8 gene ablates cell death induction by the TNF receptors, Fas/Apo1, and DR3 and is lethal prenatally. Immunity 1998;9:267-76.

49. Hakem R, Hakem A, Duncan GS, et al. Differential requirement for caspase 9 in apoptotic pathways in vivo. Cell 1998;94:339-52.

50. Madge LA, Li JH, Choi J, Pober JS. Inhibition of phosphatidylinositol 3-kinase sensitizes vascular endothelial cells to cytokine-initiated cathepsin-dependent apoptosis. J Biol Chem 2003;278:21295-306.

51. Mousavi SA, Brech A, Berg T, Kjeken R. Phosphoinositide 3-kinase regulates maturation of lysosomes in rat hepatocytes. Biochem J 2003;372:861-9.

52. Ono K, Kim SO, Han J. Susceptibility of lysosomes to rupture is a determinant for plasma membrane disruption in tumor necrosis factor alpha-induced cell death. Mol Cell Biol 2003;23:665-76.

53. Liu N, Raja SM, Zazzeroni F, et al. NF-kappaB protects from the lysosomal pathway of cell death. EMBO J 2003;22:5313-22.

54. Kuopio T, Kankaanranta A, Jalava P, et al. Cysteine proteinase inhibitor cystatin A in breast cancer. Cancer Res 1998;58:432-6.

55. Nylandsted J, Gyrd-Hansen M, Danielewicz A, et al. Hsp70 promotes cell survival by inhibiting lysosomal membrane permeabilization. J Exp Med, in press. 